Europe's Journal of Psychology 4/2009, pp. 118-127

www.ejop.org

\title{
Effect of Consumers Mood on Advertising Effectiveness
}

\author{
Ademola B. Owolabi, Ph.D. \\ Department of Psychology, \\ University of Ado-Ekiti, Nigeria
}

\begin{abstract}
It is a fact that mood-state knowledge is of particular relevance for the understanding of consumer behavior. The belief that it may be affected by the content of marketing communication and the context in which these communications appear was the basis upon which this research was conducted. This study is essentially an experimental study where a between-subject design was employed. A total of three hundred and twenty subjects were used in the experiment. Unlike some previous advertising research (e.g. Kim and Biocca, 1997) utilizing existing adverts, specifically design adverts were made for the study. Standardized 10 minute film clips were used to induce a negative or positive mood. Two scales - attitude towards using advertised products and intention to try advertised products - were employed to measure advertising effectiveness. The result revealed that subjects in the induced positive mood group have a more positive attitude and greater intention to try advertised products when compared with subjects in the induced negative mood group. This suggests that advertisers should present adverts in a context that elicits happiness'.
\end{abstract}

Key Words: induced affect; consumer attitude; intention; positive affect; negative affect

\section{Introduction}

Individuals often try to anticipate each other's mood prior to interactions and read others moods during encounters. In these ways, mood information is acquired and used informally for social and professional interactions. For example, knowledge of the boss's mood on a particular day may help an employee anticipate the boss's reactions to a request for a pay raise. Analogously, knowledge of the consumers' mood state in certain situations may provide marketers and advertisers with a more complete understanding of consumers and their reactions to marketing strategies and adverts. 
This mood-state knowledge may be particularly relevant for understanding consumer behaviour as affected by the content of marketing communications and adverts and the context in which these communications appear. Advertising typically has some positive or negative content that can trigger affective reactions (Coulter 1998). Early research on mood and persuasion indicated that people who are in a positive mood are more susceptible to persuasion than the average person. For example, Janis (1965) had some people read a persuasive message while they ate a snack and drank soda, while others simply read the message without the accompanying treats. Greater attitude changes occurred among the "munchers" than among the "food free" group. Similar effects were also found among people listening to pleasant music (McMillan and Huang, 2002).

Good feelings enhance persuasion partly by enhancing positive thinking. In a good mood, people view the world through rose-coloured glasses. They also make faster, more impulsive decisions, they rely less on systematic thinking, but more on heuristic cues (Schwarx, 1991; Garner, 2004). Because unhappy people ruminate more before reacting, they are less easily swayed by weak arguments. Thus, it has been suggested that if you cannot make a strong case, it is a smart idea to put your audience in a good mood and hope they will feel good about your message without thinking too much about it (Schwarz, 1990).

One of the reasons for this, is proposed by the 'feelings-as-information' view, that while negative moods signal to people that something is wrong in their environment and that some action is necessary, positive moods have the opposite effect; they signal that everything is fine and no effortful thought is necessary (Schawtz, 1990). As a result, people in a positive mood are more persuadable because they are less likely to engage in extensive thinking of the presented arguments than those in a neutral or negative mood.

Although the 'feelings-as-information' view contends that happy people tend to rely on peripheral route processing, an alterative cognitive response explanation - the 'hedonic contingency view' - asserts that this is not always the case (Wenger and Petty, 1994).

According to this perspective, happy people will engage in a cognitive task that allow them to remain happy and will avoid those tasks that lower their mood. Research investigating this possible effect indicated that a happy mood can indeed lead to greater message elaboration than a neutral or sad mood, when the persuasive message is either uplifting or not mood threatening (mood congruent) (Norris, Colmon and Aleixo, 2003; Coulter, 2003; Wegner, Petty and Smith, 1995). Thus, 
it appears that happy people do not always process information less than neutral or sad people. Taken together, the above studies suggest that there is a likelihood that mood has a lot of effect on the way messages are received and processed. Therefore the aim of this study is to determine whether being in a positive mood or negative mood affect audience evaluation of advertisement as effective or not effective.

Materials and Methods

Design

A between-subject experimental design was employed to test whether positive or negative affect induced by the film clips had any effect on advertising effectiveness. Advertising effectiveness was measured by attitude towards the advertised products scale and intention to buy the advertised products scale. The adverts were embedded into the positive and negative film clips.

Setting

Two laboratories in the Department of Geography and Planning Science, Faculty of the Social Science, University of Ado-Ekiti, Ekiti State were used for the study, because of their quiet situation which allowed for a carefully controlled environment.

Subjects

The research participants were three hundred and twenty (320) university undergraduates drawn from the Faculty of the Social Science. Like most other advertising research studies (e.g. Knoch and McCarthy, 2004; Fieldling et al, 2006; Shenge, 2003; Morison et al, 2003) this study was conducted using undergraduate students, but, unlike those studies, the participants were not paid for participating in the research; neither did they receive any credit on any course for their participation.

Materials

The adverstiments.

Unlike some previous advertising research (e.g., Kim and Biocca, 1997; Knap and Hall, 2006; Puccinelli, 2006), utilizing existing adverts, specifically designed adverts 
were used for this study. Two undergraduate actors (male and female) recruited through theatre organizations on a university campus served as the presenter of the adverts. Before video taping the adverts for each product, the actors memorized the product descriptions. Each person presented the two products to eliminate the likely effect of sex of the advert presenter.

Participants' mood manipulation

A 10-minute film clip was used to induce a negative or positive mood. Both the negative clip and the positive clip were extracts from a home video titled "The Bastard". The positive clip was about a family that everything was going on well for; the parents were prospering economically and in other respects, and the children were gaining admission into university. The negative aspect was how a gang of armed robbers came to wipe off the joy of the family by raping the daughter, killing the father and son and leaving the mother and daughter with psychologically traumatised. Extracting both positive and negative induced aspects from the same film made it possible to use the same set of actors.

The two clips were subjected to a rating by a conference of experts with raters expressing 100 percent rating for the sadness-eliciting clip and 70.5 percent rating for the happiness-eliciting clip. Another set of 20 undergraduates also watched and rated the clips on a ten-point scale; a reported feeling of sadness at 9.5 was recorded for the sadness eliciting clip and a happy feeling of 8.0 was recorded for the happiness eliciting clip. These mood-eliciting clips were combined with four types of advert to produce eight adverts and affect types.

Psychological instruments

Attitude towards using advertised product was measured using a modified form of Belch's Semantic Differential Scale (1981) measuring attitude towards using advertised products.

For reliability, Attitude Toward using Advertised Product Scale had a standardized coefficient alpha of 0.81 , coefficient alpha for part 1 (five-item) split-half alpha of 0.65, coefficient alpha for part 2 (five-item) split-half of 0.68 , split-half of 0.74 and overall reliability (Spearman-Brown) coefficient of 0.85 (Shenge, 2003).

For validity, there was a least correlated item-total correlation of 0.36 and a highest correlated item-total correlation of 0.61 . 
Intention to try advertised product was measured using a ten-item set of opposite-inmeaning evaluative factor adjectives earlier used by Shenge (1996). It measures subjects' intention to try the advertised product, which in real life advert practice, is also viewed by the advertiser as instrumental for unticipating the audience's final purchase of the advertised product.

For reliability, the Intention To Try Advertised Product Scale had a standardized coefficient alpha of 0.75 , coefficient alpha for part 1 (five-items) split-half coefficient alpha of 0.61 for part 2 (five-items) split-half of 0.57 , split-half of 0.62 and overall reliability (Spearman-Brown) coefficient of 0.77 .

For validity, there was a least correlated item-total correlation of 0.33 and a highest correlated item-total correlation of 0.48; also, a factor analysis result on intention showed that there was a high degree of agreement among the intention scale items (Shenge, 2003).

\section{Procedure}

Prior to the participants' admittance to the laboratory, efforts were made to minimize distraction by lowering the window blind. Efforts were also made to prevent passers-by from making a noise and distracting the subjects. Participants were randomly assigned to the various experimental groups.

After the instruction was given participants watched the film clips assigned to them. Participants were not told the relevance of the film clips to the adverts. At the end of the exercise, they rated their feelings about the adverts using the questionnaire given to them. The completed questionnaires were collected and participants were debriefed, thanked and politely sent away.

\section{Results}

Table of mean scores on advertising effectiveness as determined by sex of advert presenter, product type and mood

\begin{tabular}{|l|l|l|l|l|l|}
\hline \multicolumn{4}{|l|}{ Sex of advert presenter } & \multicolumn{3}{l|}{ Product type } & Mood & \\
\hline Male & female & masculine & feminine & positive & negative \\
\hline 39.61 & 40.99 & 41.16 & 40.05 & 44.50 & 32.05 \\
\hline
\end{tabular}


A summary of 2x2x2 ANOVA table: showing the effect of Sex of Advert Presenter, Product Type and Mood on Advertising Effectiveness.

\begin{tabular}{|l|l|c|l|l|l|}
\hline Source & SS & d f & MS & F & P \\
\hline S. A.P (A) & 126.920 & 1 & 126.920 & 1.92 & NS \\
\hline Product type (B) & 333.869 & 1 & 333.869 & 2.05 & NS \\
\hline mood (C) & 570.249 & 1 & 570.249 & 8.36 & .05 \\
\hline A X B & 38.934 & 1 & 38.984 & 0.59 & NS \\
\hline A X C & 36.475 & 1 & 36.476 & 0.55 & NS \\
\hline B X C & 108.631 & 1 & 108.631 & 1.64 & NS \\
\hline Error & 19020.135 & 288 & 66.04 & & \\
\hline Total & 612722.00 & 319 & & & \\
\hline
\end{tabular}

*S A P = Sex of advert presenter

The results revealed that induced affect had a significant effect on advertising effectiveness $(F(1,318)=8.36, P<.05)$. An observation of the mean score shows that participants in the happy mood have a more positive attitude towards the advertised product $(x=44.50)$ as compared to participants in the sad mood ( $x$ 32.05). This finding concurs with Schwarz and Clore's (1988) findings that customers will often use their feelings as information and, therefore, make judgment that are congruent with the implications of these feelings.

\section{Summary and discussion}

This study experimentally examines the effects of mood on advertising effectiveness. Sex of advert presenter and product types were build into the study to control for the possible effect that they may have on the study. Positive and negative mood were induced with the use of home video.

In measuring advertising effectiveness two criteria were combined: attitude towards advertised product and intention to try advertised product. Belch (1981), Cacioppo and Petty (1974), and Schroeder (2006) have found that multiple criteria were more efficacious in measuring of advertising effectiveness than a single criterion.

The findings reveals that there is a significant effect of mood on advertising effectiveness, but there are no significant effects of sex of advert presenter and product type on advertising effectiveness

Wegener \& Braverman (2004) provided evidence that people who are in a good mood like adverts more and are more capable and willing to process message 
information. This means that when people are in good mood they view the world through rose-coloured glasses and evaluate events around them positively (Garsper, 2004). Various mechanisms have been proposed to explain this phenomenon. According to the excitation or affect transfer hypothesis (Cantor, Zillman and Bryant 1975, Tavassoli, Shuitz and Fitzsimons 1995), the positive evaluation of the context is transferred to the advert and, as a result, the advert is also positively evaluated. Another explanation is the fact that a positive mood enhances advert processing according to the hedonistic contingency theory (e.g. Lee and Sternthal, 1999).

People in a positive mood engage in greater processing of stimulus because they believe that the consequences are going to be favourable. This explanation is similar to that advanced by Isen (1984) who stated that knowledge structure (associative networks) associated with good moods are generally more extensive and better integrated than structures that are associated with bad moods (affective priming).

Aylesworth and Mackenzie (1998) provided a different explanation for the same phenomenon. They established that television advert processing is better when people were in a positive mood after seeing a programme. Their explanation is that people who are in a bad mood after seeing a programme are still processing the programme centrally while seeing the advert, as a result of which the advert is processed peripherally. People who are in good mood after seeing a programme are less inclined to analyse it further, and, therefore, are more capable of processing the advert centrally. As a result, a media context that is well appreciated may lead to a more positive appreciation of the advert shown in that context and to more elaborate advert processing. The excitation transfer hypothesis and related theories have been confirmed in several other studies (Goldberg and Gorn, 1987; Murry, Lastovicka and Singh 1992; Lynch and Stipp, 1999).

The finding of this research lends credence to Puccineli's (2006) findings that participants in a good mood react positively to a salesperson who conveys positive feelings and are willing to pay more for the product endorsed by the person, while participants who are in a bad mood react negatively to such a person and are willing to pay less for the product.

This finding contradicts some studies that concluded that a positive mood does not lead to positive evaluation of advert, e.g., Cantor and Venus (1980), Derks and Avora (1993). In their findings, using the contrast effect of Mayers - Levy and Tybount (1997), they assert that message style that contrasts with the nature of the context may lead to positive advertising effects. 
The study suggested that a positively evaluated environmental context, or a context that evokes a positive mood, leads to a less positive advert evaluation and especially less advert processing. This phenomenon is attributed to the fact that a positive mood reduces the processing of stimulus information. According to the cognitive capacity theory, a positive mood activates an array of information in the memory that limits the recipient's processing of incoming information (Mackie and Worth, 1989).

It is worth noting that for an advert to achieve the desired aim of creating a favourable impression in the mind of the audience it seems to be useful if members of the audience are in a happy mood.

\section{References}

Aylesworh, A. B; and Mackenzie, S. B. (1998) "Context is Key: The effect of programinduced mood on thoughts about ad". Journal of Advertising, 27 (2), 7-27.

Belch, G. E. (1981) An examination of comparative and non-comparative Television Commercial: The effects of clean variation and repetition on cognitive response and message acceptance. Journal of Marketing, 28, 333-348.

Bless, H, Clore, G .L, Schwarz, N, Golisano, V, Rave C., and Work, R (1996) Mood and the use of scripts. Does being in a happy mood rely lead to mindlessness. Journal of Personality and Social Psychology.

Bless, H, Mackie, D. M and Schwarz, N (1992) Mood effects on encoding of judgmental processes in persuasion. Journal of Personality and Social Psychology, 65, 58-595.

Cantor, J. R. and Venus, P (1980) "The effect of humour on recall of a Radio advertisement" Journal of Broadcasting, 24 (1), 13-22.

Cantor, J. R; Zillman, D and Bryant J. (1975) "Enhancements of humour appreciation by transfer excitation". Journal of Personality and Social Psychology, 32, 69-75.

Coulter K. S. (1998) The effects of affective responses to media context on advertising evaluations, Journals of Advertising, 27 (4), 41-51.

Fielding, S; Hundley, M; Reid, G. and Whitehad, H. (2006) The effect of screen size and audience size on impressions of personal space when watching television. 
Gardner, M. (2004) "Mood states and consumer behaviour: A critical review" Journal of Consumer Behaviour, 12, 281-300.

Gasper, K. (2004) Do you see what I see? Affect and visual Information processing. Cognition and Emotion, 18(3), 405-421.

Goldberg, M. E. and Gorn, G. J. (1987) Happy and sad T. V. program: How they affect reactions to commercials" Journal of Consumer Research, 14 (December), 387-403.

Isen, A. M and Daubman, K. A (1984) The influence of affect on categorization. Journal of Personality and Social Psychology, 47, 1206-1217.

Janis, I. L. (1965) Facilitating effects of eating - while-reading on responsiveness to persuasive communications. Journal of Personality \& Social Psychology , 1, 181-186.

Kim, T. and Biocca (1997) Telepresence via television: Two dimensions of telepresence may have different connecting to memory and persuasion; Journal of Computer Mediated Communication. 3 (2) pp 600-613.

Knap, M. L. and Hall, J. A. (2006) Non-verbal communication in human interaction $\left(6^{\text {th }}\right.$ eds) Belmont. Thomson Wadsworth.

Knoche, H. and McCarthy, J. (2004) Mobile users needs and expectations of future multimedia services in proceedings of the WWRF 12.

Mackie, D. M. \& Worth, L. T (1989) Cognitive deficits and the mediated role of positive affect in persuasion. Journal of Personality and Social Psychology 57, 101-122.

McMillan, S.J and Huang, J.S (2002) Measures of perceived interactivity: An exploration of the role of direction of communication, user control and time in shaping perceptions of interactivity, Journal of Advertising 31, 3, 29-42.

Puccineli, N. M; (2006) The impact of customer mood on salesperson evaluation. Journal of Consumer Research, 48, (2), 39-54.

Schwarz, N and Clore, G. L (1996) Feelings and phenomenal experience. In Higgins and Kruglanski (Eds), Social Psychology; Handbook of Basic Principle. New york: Guilford.

Schwarz, N, (1990) Feelings as information: information and motivational functions of affective states. In E. T Higgins (Eds) and cognition: Formations of Social Behaviour (vol 2, 527-561) a New York, Guilford press. 
Schwarz, N, Bless, H., Bohner, G (1991) Mood and persuasive communications. In M. Zanna (Education) Theories in Experimental Social Psychology vol. 24, 161-199, San Diego, CA: Academy Press.

Shenge, N. A. (1996) An experimental study of persuasive mechanisms and the impact on television commercial efficacy. An unpublished M. Sc Dissertation submitted to the department of Psychology, University of Ibadan.

Shenge, N. A. (2003) An evaluation of pressure response and active learning advertising theories on efficacy of television commercial messages: An unpublished Doctoral thesis submitted to the department of Psychology, University of Ibadan.

Wagener, D. T., Petty, R. E and Smith, S.M (1995) Positive mood can in crease or decrease message scrutiny. Journal of Personality and Social Psychology, 69 132- 147.

Wegener, D. T and Petty, R. E. (2001) understanding effect of mood through the elaboration like hood and flexible correction models. In. L.L. Martin and G. L. Clore (eds). Theories of mood and cognition: A Users Guild Book (pp. 177-210)

Worth, L. T. and Mackie, D. M (1987) Cognitive mediation of positive persuasion. Social Cognitive, 5, 76-94.

Zillmann, D (1988a) Mood management through communication choices. American Behavioral Scientist, 31 (3), 327-341.

Zillmann, D (1988b) Mood management. Using entertainment to full advantage. In L Donohew, H. E Sypher, and E. T Higgins (Eds), Communication social cognition and affect (147-171). Hillsdale, N. J Lawrence Erilbaum Associates.

Zillmann, D (2000) Mood Management in the context of selective exposure theory. In M.F Roloff (Education), Communication yearbook 23 (103-23) Thousand Oaks, CA: Sage.

About the author:

$\operatorname{Dr}$ A. B Owolabi is a lecturer in the Department of Psychology, University of Ado Ekiti Nigeria. He is an industrial/organizational Psychologist with an interest in consumer behavior and Psychology of advertising. He has published several articles in this area.

All correspondence should be address to;

Owolabi A. B, Department of Psychology, University of Ado Ekiti, Nigeria, P. m. b 5363

E-mail: labdem2005@yahoo.ca 